\title{
A Retrospective Study of the Round Radiopaque Foreign Bodies in the Oesophagus
}

https://doi.org/10.47210/bjohns.2021.v29i2.464

\section{Syamji Venkataramana, ${ }^{1}$ Lakshmi Sameeri Khaderbad ${ }^{2}$}

\section{Introduction}

\section{ABSTRACT}

Ingested foreign bodies (FBS) of the digestive tract can be divided into radiolucent and radiopaque, based on their appearance in Roentgenogram. Coins and button-batteries (BBS) constitute majority of the radiopaque FBs that are round in shape.

Materials and Methods

Medical records of children admitted with foreign bodies in the GI tract during the last 5 years have been reviewed. We have taken into our study, round radio-opaque FBs and analyzed the results.

$\underline{\text { Results }}$

Out of 120 radiopaque FBs, in 112 cases they are lodged in cricopharyngeal sphincter (CPS), which were removed. Of these, 103 were coins and 9 were BBs. Five coins, which had crossed the CPS, ultimately passed out naturally with faeces. Three $B B s$, impacted in the oesophagus, distal to the CPS, were removed via esophagoscopy, on emergency basis. One child with impacted BB developed mediastinitis and died.

\section{Conclusion}

A round opaque disc shaped FB which is impacted or seen below CPS should not be treated as coin every time. High index of suspicion is needed to rule out BB ingestion as it is associated with high morbidity and mortality. Aim of this study is to stress on the need for educating primary care physicians and rural medical practitioners to avoid wait and watch policy, thus reducing misdiagnosis of coins for BBs.

$\underline{\text { Keywords }}$

Foreign Bodies; Radiopaque; Gastrointestinal Tract; Esophagus; Child

M any times a patient presents with history of accidental ingestion of foreign body (FB). They are usually lodged in the crico-pharyngeal sphincter (CPS). Most of the times it is a known object in children, when watched by intelligent or educated

1 - Department of ENT and Head and Neck

Surgery,Bhaskara Medical College, Moinabad, Rangareddy Dist, Telangana

2 - Department of ENT and Head and Neck Surgery,

Maheshwara Medical College, Chitkul, Medak Dist,

Telangana

\section{Corresponding author:}

Dr Lakshmi Sameeri Khaderbad

email: drsameerient@gmail.com parents. In case of illiterate or uneducated parents, child is most often allowed to play on the floor without supervision. In case any small objects are carelessly left on the floor and accidentally ingested by unsupervised child, he/she may develop sudden onset of difficulty in swallowing, sometimes choking and asphyxiation. There is also a wide range of clinical presentations with mild symptoms to potential complications, making the condition difficult to evaluate. ${ }^{1-4}$ Most of the times, these FB ingestions are seen in children between age groups of 6 months to 5 years. ${ }^{5,6}$ Majority of the times i.e. almost $80 \%$ of GI foreign bodies pass spontaneously, around $10-20 \%$ require endoscopic removal, around $1 \%$ require external surgery. ${ }^{7-11}$ Radio-opaque FBs are, most of the times, objects like coins, safety pins, scarf pins, screws, 
Table I: Site of presence/impaction of round radiopaque foreign bodies in the upper digestive tract at the time of presentation

\begin{tabular}{|l|c|c|c|}
\multicolumn{1}{c|}{$\begin{array}{c}\text { SITE OF PRESENCE / } \\
\text { IMPACTION }\end{array}$} & COIN & BUTTON BATTERY & TOTAL \\
\hline At the level of CPS & 103 & 9 & 112 \\
\hline Below the level of CPS & 5 & 3 & 8 \\
\hline Total & 108 & 12 & 120 \\
\hline
\end{tabular}

button batteries etc. ${ }^{12,13}$ Non-metal radiopaque FBs are usually animal bones. Thin fish bones, plastic and rubber items are non radio-opaque. ${ }^{14} \mathrm{FBs}$ usually passed in a day or two, transit time depends on their size, and the guidelines contain very limited information on the size of the foreign body and transit time. ${ }^{14-16}$

\section{Materials and Methods}

The medical records of children with radio-opaque FBs in GI tract, admitted in our hospital, were reviewed for a period of five years, i.e. from December 2015 to December 2020. The FBs are divided into round, irregular and specific shaped depending on the nature of objects.

Round shaped FBs particularly coins, followed by button batteries are particularly presented in children

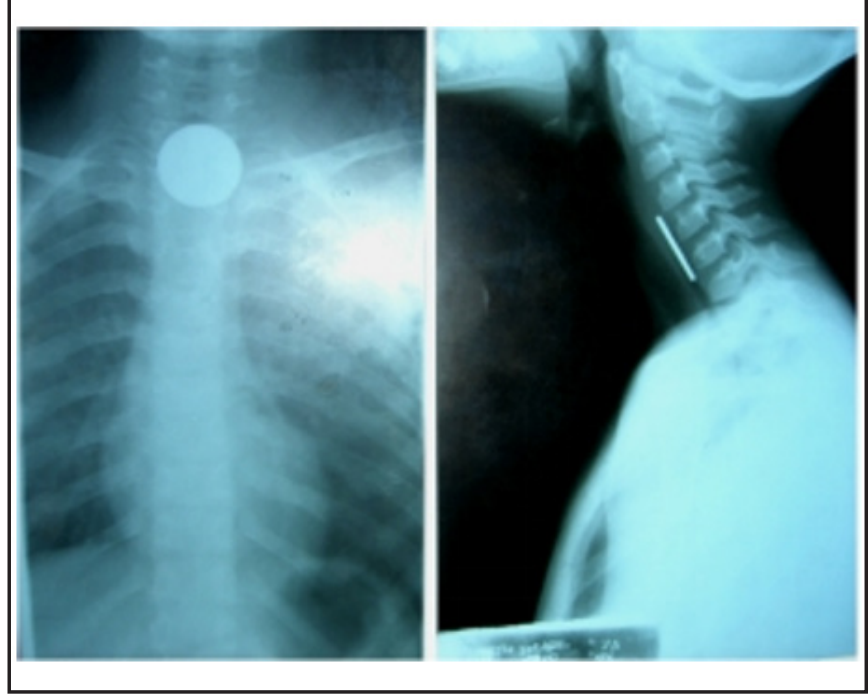

Fig.1. Foreign body (coin) at the level of cricopharynx below the age group of 5 years. Irregularly shaped FBs (bizarre) are seen in children and adults who are basically psychiatric patients. Specific shaped foreign bodies like safety pins, needles, animal bones are seen in children as well as adults. We have taken into our study, round radiopaque foreign bodies and analyzed the results.

\section{Results}

252 patients of gastrointestinal foreign bodies are observed, out of which $120(47.6 \%)$ are radiopaque and rounded. Remaining 132 (52.3\%) are either irregular shaped or specific shaped like safety pins, needles and screws or radiolucent.

Out of 120 radio-opaque foreign bodies, around 108 $(90 \%)$ were found to be coins. Remaining 12 (10\%) were Lithium Ion button batteries (BB). (Table I) Most of the times i.e. in 112 cases $(93.3 \%)$ they are lodged in CPS (Fig.1) which were removed. Of these, 103 were found to be coins $(91.96 \%)$ and 9 were found to be button batteries $(8.03 \%)$.

Remaining foreign bodies $8(6.66 \%)$ were found below CPS and not passed down the oesophagus at the time of presentation. Among these, 5 FBs were coins which passed down in 1-2 days as observed in sequential X-rays (Fig.2). Three BBs, detected radiologically in the oesophagus (Fig.3), were removed via esophagoscopy under general anaesthesia, on emergency basis.

Percentage of coins among the FBs that crossed CPS and passed down the GI tract uneventfully is $100 \%$ i.e., all the coins which crossed the CPS have traversed the esophagus without any intervention.

None of the BBs $(0 \%)$ could traverse the whole length 


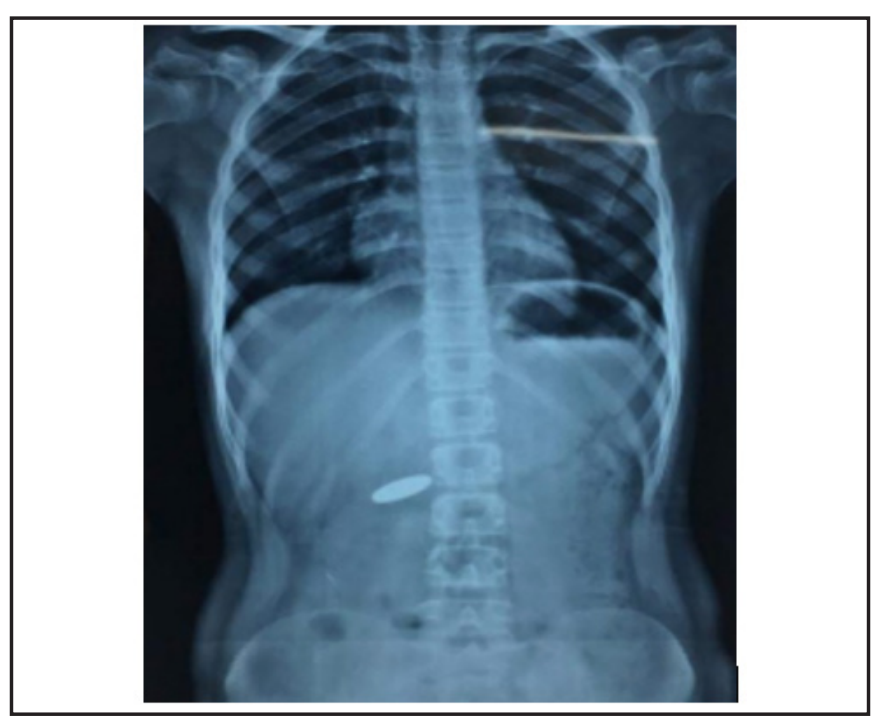

Fig.2. Foreign body (coin) passed into lower digestive tract

of esophagus after crossing CPS i.e., all the $3 \mathrm{BBs}$ that crossed the CPS, have stayed in the oesophagus only, requiring endoscopic removal. One, of these 3 cases, died of mediastinitis, which developed 24 hours after removal of the object.

\section{Discussion}

As coins and button batteries (BB) both are round, disc shaped and are available in different sizes, there is a high chance of mistaking the $\mathrm{BB}$ ingestion for coins. Sometimes these patients, particularly those cases where FB is lodged below CPS were not admitted in other hospitals with the idea that these objects would pass down. Two such patients reached our hospital around three days after ingestion, with persistent symptoms leading to suspicion of a FB other than coin. Without further delay, patients were evaluated, prepared, esophagoscopy was done under general anaesthesia, and Li-Ion BBs were removed.

In a study conducted by Arora et.al, 92\% of ingested radiopaque round foreign bodies were coins and rest of $7.09 \%$ were BBs. In our study, round opaque foreign bodies constituted for around $47.6 \%$, of which nearly $90 \%$ are coins and BBs constitute around 10\%. Though the incidence of $\mathrm{BB}$ ingestion has been constantly rising

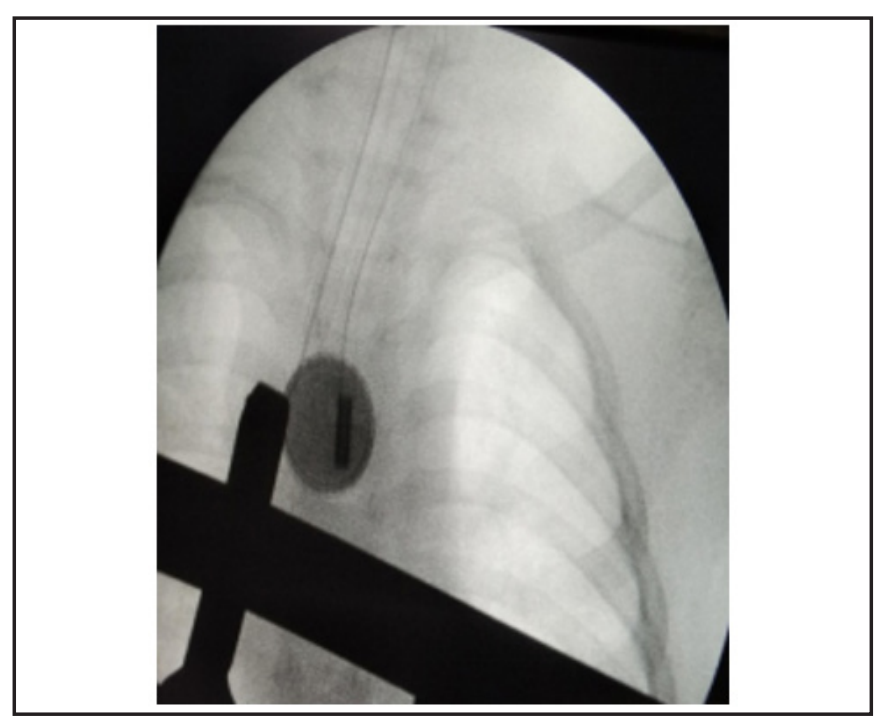

Fig.3. Button battery (with double halo appearance) in esophagus

in the past two decades, still major proportion are coins only.

Of the 112 radiopaque FBs, which lodged at CPS (93.3\%), $103(91.96 \%)$ were coins and $9(8.03 \%)$ were BBs. Of the $8 \mathrm{FBs}(6.66 \%$ of total) which passed down the CPS, 5 (62.8\%), passed down the oesophagus and gastrointestinal tract uneventfully and all were found to be coins. Rest three $(37.5 \%)$ were BBs, which were removed endoscopically under general anaesthesia as emergency procedure. One of these 3 cases has succumbed to mediastinitis which he developed 24 hours after removal of BB.

Site of impaction was cricopharynx in $75 \%$ of BBs in our study, it is in accordance to reported $74.3 \%$; but impaction of coins was $95.3 \%$ in our study, contrary to that reported by Arora et.al, ${ }^{17}$ i.e., $60.3 \%$. This variation can be attributed to rural background of the area in which our institute is situated. Spontaneous expulsion is seen in $5(4.62 \%)$ of coins, which depends on size of the object. Mortality rate of BB ingestion is $23.1 \%$ and $6.3 \%$ in studies conducted by Leinwand et al. ${ }^{18}$ and Krom et al. ${ }^{19}$ respectively. In our study it is $8.33 \%$ for the ingested BBs. 


\section{Conclusion}

Impaction of the foreign body depends on its size and age of the child. Most of the times coins get impacted at the CPS and those which have crossed the sphincter easily pass down without any complications.

But, BBs, either lodged at the CPS or below the esophagus immediately start corrosive mucositis due to alkaline, thermal and electrical actions. These can damage mucosa and gut wall within minutes to hours can lead to fatal complications like mediastinitis and aorto enteric fistula. High index of suspicion is required to avoid delays in diagnosing as it reflects directly on morbidity and mortality.

At this point of time, a round opaque disc shaped foreign body which is impacted or seen below CPS should not be treated as coin every time, as use of BBs is increasing in day-to-day life and circulation of coins is decreasing. Aim of this study is to stress on the need for educating primary care physicians and rural medical practitioners about such mis-diagnosis of coins for BBs, which can save lives of hundreds of children.

\section{References}

1. Anderson KL, Dean AJ. Foreign bodies in the gastrointestinal tract and anorectal emergencies. Emerg. Med. Clin. North Am. 2011; 29(2):369-400

2. Al Lawati TT, Al Marhoobi RM. Timing of button battery removal from the upper gastrointestinal system in children. Pediatr Emerg Care. 2018 Dec 27. doi: 10.1097/ PEC.0000000000001697

3. Zhang XR, Li Q. [A case of magnetic pharyngeal foreign body in children]. Lin Chung Er Bi Yan Hou Tou Jing Wai Ke Za Zhi. 2018; 32(18):1432-3. Chinese. doi: 10.13201/j.issn.10011781.2018.18.017

4. Malik SA, Qureshi IA, Muhammad R. diagnostic accuracy of plain x-ray lateral neck in the diagnosis of cervical esophageal foreign bodies keeping oesophagoscopy as gold standard. J Ayub Med Coll Abbottabad. 2018; 30(3):386-8

5. Lee, JH, Lee JH, Shim JO, Lee JH, et al. Foreign body ingestion in children: should button batteries in the stomach be urgently removed? Pediatr Gastroenterol Hepatol Nutr. 2016; 19:20-8. doi: $10.5223 /$ pghn.2016.19.1.20

6. Wyllie R. Foreign bodies in the gastrointestinal tract. Curr Opin Pediatr. 2006; 18:563-4. doi: 10.1097/01. mop.0000245359.13949.1c

7. Lee JH, Lee JS, Kim MJ, Choe YH. Initial location determines spontaneous passage of foreign bodies from the gastrointestinal tract in children. Pediatr Emerg Care 2011; 27:284-9. doi: 10.1097/PEC.0b013e318213131a

8. Kay M, Wyllie R. Pediatric foreign bodies and their management. Curr Gastroenterol Rep. 2005; 7:212-8. doi: 10.1007/s11894-005-0037-6

9. Sung SH, Jeon SW, Son HS, Kim SK, et al. Factors predictive of risk for complications in patients with oesophageal foreign bodies. Dig Liver Dis. 2011; 43:632-5. doi: 10.1016/j. dld.2011.02.018

10. Beata R, Grazyna N, Artur N, Ewa RD, Pawel R. Esophageal foreign bodies in pediatric patients: a thirteen-year retrospective study. Sci World J. 2012; 2012:102642. doi: $10.1100 / 2012 / 102642$

11. Arana A, Hauser B, Hachimi-Idrissi S, Vandenplas Y. Management of ingested foreign bodies in childhood and review of the literature. Eur J Pediatr. 2001; 160:468-72. doi: $10.1007 / \mathrm{s} 004310100788$

12. Lee JH, Kim HC, Yang DM, Kim SW, et al. What is the role of plain radiography in patients with foreign bodies in the gastrointestinal tract? Clin Imaging 2012; 36:447-54. doi: 10.1016/j.clinimag.2011.11.017

13. Nation J, Jiang W. The utility of a handheld metal detector in detection and localization of pediatric metallic foreign body ingestion. Int J Pediatr Otorhinolaryngol. 2017; 92:1-6. doi: 10.1016/j.ijporl.2016.10.035

14. ASGE Standards of Practice Committee, Ikenberry SO, Jue TL, Anderson MA, Appalaneni V, Banerjee S, et al. Management of ingested foreign bodies and food impactions. Gastrointest Endosc. 2011; 73:1085-91. doi: 10.1016/j.gie.2010.11.010

15. Tringali A, Thomson M, Dumonceau JM, Tavares M, et al. Pediatric gastrointestinal endoscopy: European Society of Gastrointestinal Endoscopy (ESGE) and European Society for Paediatric Gastroenterology Hepatology and Nutrition (ESPGHAN) Guideline Executive summary. Endoscopy 2017; 49:83-91. doi: 10.1055/s-0042-111002

16. Birk M, Bauerfeind P, Deprez PH, Häfner M, et al. Removal of foreign bodies in the upper gastrointestinal tract in adults: European Society of Gastrointestinal Endoscopy (ESGE) Clinical Guideline. Endoscopy 2016; 48:489-96. doi: 10.1055/ s-0042-100456

17. Arora R, Kumar S, Singh GB et al. Predictors of nature of ingested foreign bodies in children \& assessment of operative outcomes: Int J Pediatr Otorhinolaryngol. 2018 Oct; 113:15055

18. Leinwand K, Brumbaugh DE, Kramer RE. FASGE Button battery ingestion in children: A paradigm for management of severe pediatric foreign body ingestions: Gastrointest Endosc Clin N Am. 2016; 26(1): 99-118

19. Krom H, Visser M, Hulst JM, et.al. Serious complications after button battery ingestion in children. Eur J Pediatr. 2018; 177(7): 1063-70. 